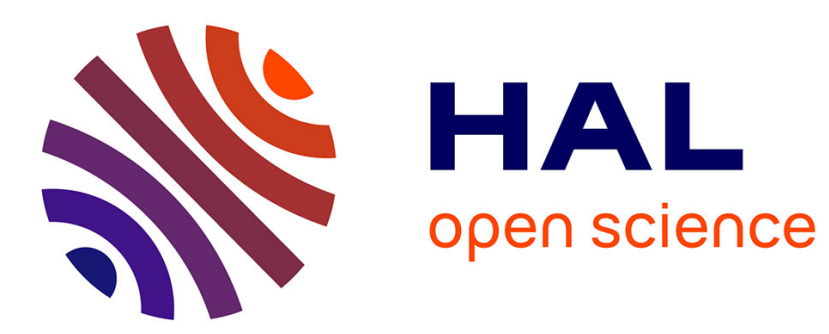

\title{
Cryoglobulinemia Vasculitis
}

Patrice Cacoub, Cloe Comarmond, Fanny Domont, Léa Savey, David Saadoun

\section{To cite this version:}

Patrice Cacoub, Cloe Comarmond, Fanny Domont, Léa Savey, David Saadoun. Cryoglobulinemia Vasculitis. The American Journal of Medicine, 2015, 128 (9), pp.950-955. 10.1016/j.amjmed.2015.02.017 . hal-01142000

\section{HAL Id: hal-01142000 https: / hal.sorbonne-universite.fr/hal-01142000}

Submitted on 14 Apr 2015

HAL is a multi-disciplinary open access archive for the deposit and dissemination of scientific research documents, whether they are published or not. The documents may come from teaching and research institutions in France or abroad, or from public or private research centers.
L'archive ouverte pluridisciplinaire HAL, est destinée au dépôt et à la diffusion de documents scientifiques de niveau recherche, publiés ou non, émanant des établissements d'enseignement et de recherche français ou étrangers, des laboratoires publics ou privés. 


\section{Cryoglobulinemia Vasculitis}

Patrice Cacoub ${ }^{1,2,3,4}$, MD, Cloe Comarmond ${ }^{1,2,3,4}$ MD, Fanny Domont ${ }^{1,4}$ MD, Léa Savey ${ }^{1,4}$ MD, David Saadoun, MD, PhD ${ }^{1,2,3,4}$

${ }^{1}$ Sorbonne Universités, UPMC Univ Paris 06, UMR 7211, and InflammationImmunopathology-Biotherapy Department (DHU i2B), F-75005, Paris, France

2 INSERM, UMR_S 959, F-75013, Paris, France

${ }^{3}$ CNRS, FRE3632, F-75005, Paris, France

${ }^{4}$ AP-HP, Groupe Hospitalier Pitié-Salpêtrière, Department of Internal Medicine and Clinical Immunology,F-75013, Paris, France

2079 words, abstract 247 words, 30 references, 2 tables, 3 Figures

Key words: cryoglobulins, cryoglobulinemia vasculitis, HCV, prognosis, treatment

\section{Funding sources: none}

\section{Conflict of interest}

- Pr Patrice Cacoub has received consultancies, honoraria, advisory board, speakers' fees from Abbvie, Astra Zeneca, Bayer, Boehringer Ingelheim, Gilead, Glaxo Smith Kline, Janssen, Merck Sharp Dohme, Pfizer, Roche, Servier, and Vifor.

- Pr Patrice Cacoub is an inventor of a patent application owned by his academic institution and licensed to ILTOO pharma, a biotechnology company developing low dose IL-2 in autoimmune diseases, in which in holds shares.

- Dr David Saadoun has received consultancies, honoraria, advisory board, speakers' fees from Astra Zeneca, Medimmune, and Gilead.

- Dr Cloe Comarmond has nothing to disclose.

- Dr Fanny Domont has nothing to disclose.

- Dr Léa Savey has nothing to disclose. 
All authors had access to the data and had a role in writing the manuscript.

Running head: Cryoglobulinemia

Correspondence: Prof. Patrice CACOUB, MD, AP-HP, Hôpital Pitié-Salpêtrière,

Département de Médecine Interne et d'Immunologie Clinique, Paris, F-75013 France Tel.: + 331421780 27. Fax: + 331421780 33. E-mail: patrice.cacoub@psl.aphp.fr 


\section{Abstract}

Cryoglobulinemic vasculitis (CryoVas) is a small vessel vasculitis involving mainly the skin, the joints, the peripheral nerve system and the kidneys. Type I CryoVas are single monoclonal immunoglobulins related to an underlying B-cell lymphoproliferative disorder. Type II and III cryoglobulins, often referred to as mixed cryoglobulinemia, consist of polyclonal $\lg G$ with or without monoclonal $\lg \mathrm{M}$ with rheumatoid factor activity. Hepatitis $\mathrm{C}$ virus $(\mathrm{HCV})$ infection represents the main cause of mixed CryoVas. The 10-year survival rates are $63 \%, 65 \%$ and $87 \%$ in HCV-positive mixed CryoVas, HCV-negative mixed CryoVas and type I CryoVas patients, respectively. In HCV-positive patients, baseline poor prognostic factors include the presence of severe liver fibrosis, and central nervous system, kidney, and heart involvement. Treatment with antivirals is associated with a good prognosis whereas use of immunosuppressant (including corticosteroids) is associated with a poor outcome. In HCV-negative patients, pulmonary and gastrointestinal involvement, renal insufficiency and age $>65$ years are independently associated with death. Increased risk of lymphoma should also be underlined. Treatment of type I CryoVas is that of the hemopathy; specific treatment also include plasma exchange, corticosteroids, rituximab and ilomedine. In HCV-CryoVas with mild to moderate disease, an optimal antiviral treatment should be given. For HCVCryoVas with severe vasculitis (i.e. worsening of renal function, mononeuritis multiplex, extensive skin disease, intestinal ischemia...) control of disease with rituximab, with or without plasmapheresis, is required before initiation of antiviral therapy. Other immunosuppressants should be given only in case of refractory forms of CryoVas, frequently associated with underlying B-cell lymphoma. 
Cryoglobulins are immune complexes that may induce systemic vasculitis, a small vessel vasculitis involving mainly the skin, the joints, the peripheral nerve system and the kidneys. During the last twenty five years, major progresses have been done after the discovery of the hepatitis $\mathrm{C}$ virus $(\mathrm{HCV})$, which represents the main cause of cryoglobulins (1-4).

\section{Cryoglobulinemia spectrum and diagnostic tests}

Cryoglobulins are defined by the presence of circulating immunoglobulins that precipitate as serum is cooled below core body temperature and resolubilize when rewarmed. Cryoglobulinemia is confirmed by the detection of protein that precipitates in the patient's serum maintained at $4^{\circ} \mathrm{C}$ during at least 7 days, and which dissolved when heated at $37^{\circ} \mathrm{C}$. In most expert center, patients are considered to have a significant cryoglobulin level when > $0.05 \mathrm{~g} / \mathrm{L}$ on two determinations (4-6). The benefit of the detection of cryoglobulinemia is the excellent diagnostic performance for cryoglobulinemic vasculitis in the context of clinical symptoms evocative of vasculitis, such as purpura, peripheral neuropathy or glomerulonephritis. After detection, cryoglobulinemia is categorized by immunochemical analysis into three types (4). Type I cryoglobulins are single monoclonal immunoglobulins always linked to a B-cell lymphoproliferative disorder (7). Type II cryoglobulins consist of polyclonal IgG with monoclonal IgM with rheumatoid factor activity. Types III cryoglobulins are comprised of polyclonal $\lg G$ and polyclonal $\lg M$ with rheumatoid factor activity. Type II and III are often referred to as mixed cryoglobulinemia. Some laboratories characterize cryoglobulinemia using immunofixation or immunoelectrophoresis, and quantify the cryoglobulin level by determining the cryocrit as the percentage of the total volume (by using appropriate tube). The use of immunoblotting for immunochemical characterization is a sensitive and specific method allowing a full identification in $98 \%$, in comparison with immunofixation and immunoelectrophoresis in which identification is possible in only 54 and $28 \%$, respectively. Limitations of testing methods are that each of the immunochemical assays previously described may be influenced by artifacts arising from ex vivo cryoprecipitation after blood drawing. In consequence, when a cryoglobulin is suspected, serum should be kept warm, and tests should be carried out at $37^{\circ} \mathrm{C}$. 
Other laboratory surrogate markers, easier to detect than cryoglobulins, may provide indirect evidence of the presence of cryoglobulinemia such as low C4 serum complement fraction, decreased total hemolytic complement levels and/or presence of a monoclonal immunoglobulin or rheumatoid factor activity. Serum cryoglobulin may also interfere with a variety of laboratory tests and have been associated with spurious quantitation of plasma proteins and erythrocyte sedimentation rate, pseudo-leucocytosis, pseudo-thrombocytosis or pseudo-macrocytosis.

\section{Main features of cryoglobulinemic vasculitis}

The disease expression is variable, ranging from mild clinical symptoms (fatigue, purpura, arthralgia) to fulminant life-threatening complications (glomerulonephritis, widespread vasculitis)(1-3,6)(Table 1).

Fatigue is the main symptom, noted in $80-90 \%$ of patients. The main cutaneous sign is a palpable purpura which is reported in 70 to $90 \%$ of patients, but cutaneous ulcers may occur. It always begins at the lower limbs and may extend to abdominal area, less frequently to the trunk and upper limbs. It persists 3 to 10 days with a residual brownish pigmentation. Raynaud's syndrome and acrocyanosis, which may evolve to digital ulcerations, can occur. Arthralgia is reported in $40-60 \%$ of patients. Joint pains are bilateral and symmetric, nondeforming and involved mainly knees and hands, more seldom elbows and ankles. Frank arthritis is reported in less than $10 \%$ of patients. Neurologic manifestations range from pure sensory axonopathy to mononeuritis multiplex (60-70\%). The most frequently described form is a distal sensory or sensory-motor polyneuropathy. Polyneuropathy usually presents with painful, asymmetric paresthesia which later become symmetric. Motor deficit is inconstant and mainly affects the lower limbs, appearing a few months to a few years after sensory symptoms. Involvement of the central nervous system $(<10 \%)$ may manifest as stroke, epilepsy or cognitive impairment. Renal manifestations are reported in 20 to $35 \%$ of patients. The most frequent clinical and pathological picture is that of acute or chronic type-I membranoproliferative glomerulonephritis with sub-endothelial deposits. It represents more than $80 \%$ of cryoglobulinemic renal diseases. It is strongly associated with the presence of 


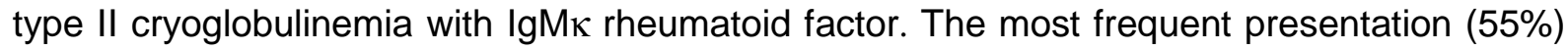
is proteinuria with microscopic hematuria and a variable degree of renal insufficiency. A sicca syndrome has been reported in $20-40 \%$ of patients. However, those meeting definite Sjögren's syndrome are rarely encountered. Other manifestations are rare $(<5 \%)$. Abdominal pains and gastrointestinal bleeding secondary to mesenteric vasculitis has been described. Cardiac involvement include mitral valvular damage, coronary vasculitis complicated by myocardial infarction, pericarditis or congestive cardiac failure. Lungs can be involved usually without clinical symptoms but some patients may present moderate exercise dyspnoea, dry cough, interstitial lung fibrosis, pleural effusions, or haemoptysis, which can be the consequence of pulmonary intra-alveolar haemorrhages.

\section{Prognosis of cryoglobulinemia vasculitis}

Cryoglobulinemia vasculitis is associated with significant morbidity and mortality. Some studies before the HCV era underlined the bad prognosis factor of renal involvement (8). More recent studies described the prognosis of patients with HCV-positive and HCV-negative mixed cryoglobulinemia vasculitis and identified prognostic factors of survival (9-11). Survival according to the type of cryoglobulinemia and HCV status is represented in Figure 1.

In HCV-positive patients with mixed cryoglobulinemia vasculitis, the 1-year, 3-year, 5-year, and 10 -year survival rates were $96 \%, 86 \%, 75 \%$, and $63 \%$, respectively. Deaths were mainly related to serious infections and end-stage liver disease (11). Baseline factors associated with a poor prognosis were the presence of severe liver fibrosis [Metavir fibrosis score $\geq$ 3](HR 5.31), central nervous system involvement (HR 2.74), kidney involvement (HR 1.91), and heart involvement (HR 4.2). The Five-Factors Score (FFS)(12), a vasculitis scoring system based on five clinical items (proteinuria $>1 \mathrm{gr} /$ day, serum creatinine $>140 \mu \mathrm{mol} / \mathrm{L}$, cardiomyopathy, severe gastrointestinal involvement and central nervous system involvement) with the presence of each being accorded 1 point, was significantly associated with outcome. In multivariate analysis, severe fibrosis (HR 10.8) and the FFS (HR 2.49) were significantly associated with a poor prognosis. Among patients without severe fibrosis, the FFS was a good predictor of outcome, while among those with severe fibrosis, the severity of 
vasculitis had no prognostic value. Treatment with the combination of Pegylated interferon plus ribavirin was associated with a good prognosis (HR 0.34), whereas treatment with immunosuppressive agents (including corticosteroids) was associated with a poor outcome, even after adjustment for the severity of vasculitis (HR 4.05)(11).

Baseline factors associated with prognosis in patients with non-infectious mixed cryoglobulinemia vasculitis have been recently reported in a large study $(13,14)$. One-year, 2-year, 5-year and 10-year overall survival rates were $91 \%, 89 \%, 79 \%$ and $65 \%$, respectively. Deaths were related to serious infections in half of cases and to vasculitis flare in $20 \%$. Pulmonary and gastrointestinal involvement, glomerular filtration rate $<60 \mathrm{ml} / \mathrm{min}$ and age $>65$ years were independently associated with death. A prognostic score including these 4 variables, the CryoVas Score (CVS), for the prediction of survival at 5 years was devised. One point score was assigned to each prognostic variable. At 5 years the death rates were $2.6 \%, 13.1 \%, 29.6 \%$ and $38.5 \%$ for a CVS of $0,1,2$ and $\geq 3$, respectively. At 1 year the death rates were $0 \%, 3.2 \%, 18.5 \%$ and $30.8 \%$ for a CVS of $0,1,2$ and $\geq 3$, respectively. The area under the curve for the CVS was higher compared with the FFS, indicating a better performance of the CVS (14). Increased risk of lymphoma in the follow up of such patients should also be underlined (15).

Data on the prognosis of type I cryoglobulinemia vasculitis has been recently reported on a series of 64 patients (7). The 1-year, 3-year, 5-year and 10-year survival rates were 97\%, $94 \%, 94 \%$ and $87 \%$, respectively. Type I cryoglobulinemia vasculitis related to hematologic malignancy tended to be associated with a poorer prognosis compared to monoclonal gammopathy of unknown significance. Severe infections accounted for half of the deaths.

\section{Management}

The production of cryoglobulins is most often the consequence of an underlying disorder that needs an etiological check-up. It depends, at least in part, according to the immunochemical determination (Figure 2). Main causes are summarized in Table 2.

In type I cryoglobulinemia vasculitis, it is mandatory to look for the presence of an underlying B-cell lymphoproliferative disorder, mainly Waldenström macroglobulinemia, multiple 
myeloma or monoclonal gammopathy of unknown significance. Type I cryoglobulinemic vasculitis are life-threatening because of the severity of cutaneous and visceral involvement and the underlying hematological disorder (7). Treatment of cryoglobulinemic vasculitis is that of the B-cell lymphoproliferative disorder. Specific treatment may also be indicated, including plasma exchange, corticosteroids, rituximab or ilomedine $(7,16)$.

In type II and III cryoglobulinemia (mixed cryoglobulinemia), the main etiological agent is by far HCV infection (70-90\%). HCV-induced mixed cryoglobulinemic vasculitis manifestations respond to clearance of HCV, i.e. sustained virologic response (SVR). During the decade 2002-2012, using a combination antiviral therapy with Pegylated interferon (PegIFN) plus ribavirin for twelve months permitted to achieve a SVR in $50-60 \%$ of patients $(17,18)$. Patients who relapsed for HCV infection after responding to antiviral therapy usually relapsed for the vasculitis with the return of viremia (19). In case of persistent mixed cryoglobulin, relapse of vasculitis might also occur in a few patients despite achieving a SVR. In such patients, a different underlying condition should be considered, especially B-cell lymphoma (20). Recent use of triple HCV therapy with PegIFN/ribavirin and a specifically-targeted antiviral agent (NS3/4A protease inhibitor, i.e. boceprevir or telaprevir) led to improved SVR rates $(65-70 \%)$ in HCV genotype 1 infection $(21,22)$. However, such combination should be given for 48 weeks and serious adverse events occurred in up to $47 \%$ of patients (21). Other direct-acting antivirals are now becoming available. The NS3/4A inhibitor simeprevir and NS5B inhibitor sofosbuvir have recently been licensed. These agents facilitate the use of shortened courses of combination IFN-free therapy, which are associated with high (>95\%) SVR rates and relatively few toxicities. International guidelines (i.e. EASL 2014)(23) state that treatment should be scheduled, not deferred, for patients with significant liver fibrosis and those with significant extra-hepatic manifestations, such as symptomatic cryoglobulinemia. As far as SVR has been previously associated to mixed cryoglobulinemia vasculitis remission in most patients, no doubt that new HCV treatments should add a major benefit. Rituximab is an interesting therapy in mixed cryoglobulinemia vasculitis, as it targets B-cells, which are responsible for cryoglobulin production and finally vasculitis lesions (24). A 
randomized controlled trial in 57 patients with HCV-mixed cryoglobulinemia vasculitis showed that rituximab has a better efficacy than conventional treatment (i.e. corticosteroids, azathioprine, cyclophosphamide, or plasmapheresis)(25). Similar results have been reported in a placebo controlled trial (26). Two controlled clinical trials showed that rituximab plus PegIFN/ribavirin compared to PegIFN/ribavirin led to a shorter time to clinical remission, better renal response rate, and higher rates of cryoglobulin clearance $(27,28)$. The use of rituximab was shown to be safe in $\mathrm{HCV}$ infected patients, in contrast with what was observed in hepatitis B virus infected patients.

To summarize, the management must be individualized according to the underlying disorder and the severity of disease. In HCV-mixed cryoglobulinemia vasculitis with mild to moderate disease, an optimal antiviral treatment should be given (Figure 3). For patients with severe vasculitis (i.e. worsening of renal function, mononeuritis multiplex, extensive skin disease, intestinal ischemia...) control of disease with rituximab, with or without plasmapheresis, is usually required before initiation of antiviral therapy. Room for other treatment strategies is very limited. Low-dose corticosteroids may help to control minor intermittent inflammatory signs such arthralgia but do not succeed in case of major organ involvement. Other immunosuppressant should be given only in case of refractory forms of HCV-mixed cryoglobulinemia vasculitis, frequently associated with underlying B-cell lymphoma (29).

\section{Follow up}

During immunosuppressive and/or antiviral treatment (for HCV-related cryoglobulinemia vasculitis), signs and symptoms gradually improve, varying from weeks (i.e. purpura, glomerulonephritis, arthralgia) to months (peripheral neuropathy). With treatment, most patients can achieve a partial or complete remission. In HCV-related cryoglobulinemia vasculitis, the clinical and immunological response is closely related to the viral response. During treatment, biological improvement can be assessed by the quantification of cryoglobulinemia and other surrogate markers ( $\mathrm{C} 4, \mathrm{CH} 50$, rheumatoid factor). The time course of HCV viral load also represents a major predictive factor of long term outcome. 


\section{ACCEPTED MANUSCRIPT}

Long-term outcome is dependent on the occurrence of complications. Patients with nonHCV-related cryoglobulinemia vasculitis have an increased risk of death, primarily due to sepsis, and a 4-fold increased risk of developing B-cell non-Hodgkin lymphoma (13). In HCVrelated cryoglobulinemia vasculitis, the overall risk of B-cell non-Hodgkin lymphoma is about 35 times higher than in the general population (30). These patients are also exposed to HCV chronic infection-induced liver disease, i.e. liver fibrosis, cirrhosis and hepatocellular carcinoma. 


\section{REFERENCES}

1. Terrier B, Cacoub P. Cryoglobulinemia vasculitis: an update. Curr Opin Rheumatol. 2013 Jan;25(1):10-8.

2. Cacoub P, Poynard T, Ghillani P, Charlotte F, Olivi M, Piette JC, Opolon P. Extrahepatic manifestations of chronic hepatitis C. MULTIVIRC Group. Multidepartment Virus C. Arthritis Rheum. 1999 Oct;42(10):2204-12.

3. Ferri C, Mascia MT, Saadoun D, Cacoub P. Cryoglobulinemia and systemic manifestations of hepatitis C. in EULAR Compendum on Rheumatic Diseases. Bijlsma JWJ Ed. Affinity 2009. pp 616-34

4. Brouet JC, Clauvel JP, Danon F, Klein M, Seligmann M. Biologic and clinical significance of cryoglobulins. A report of 86 cases. Am J Med 1974;57(5):775-88.

5. Musset L, Diemert MC, Taibi F, Thi Huong Du L, Cacoub P, Leger JM, et al. Characterization of cryoglobulins by immunoblotting. Clin Chem. 1992 Jun;38(6):798802.

6. Trejo O, Ramos-Casals M, García-Carrasco M, Yagüe J, Jiménez S, de la Red G, et al. Cryoglobulinemia: study of etiologic factors and clinical and immunologic features in 443 patients from a single center. Medicine (Baltimore). $2001 \mathrm{Jul} ; 80(4): 252-62$.

7. Terrier B, Karras A, Kahn JE, Le Guenno G, Marie I, Benarous L, et al. The spectrum of type I cryoglobulinemia vasculitis: new insights based on 64 cases. Medicine (Baltimore). 2013 Mar;92(2):61-8.

8. Tarantino A, Campise M, Banfi G, Confalonieri R, Bucci A, Montoli A, Colasanti G, Damilano I, D'Amico G, Minetti L, et al.: Long-term predictors of survival in essential mixed cryoglobulinemic glomerulonephritis. Kidney Int 1995, 47:618-623.

9. Ferri C, Sebastiani M, Giuggioli D, Cazzato M, Longombardo G, Antonelli A, et al. Mixed cryoglobulinemia: demographic, clinical, and serologic features and survival in 231 patients. Semin Arthritis Rheum 2004, 33:355-374.

10. Della Rossa A, Tavoni A, D'Ascanio A, Catarsi E, Marchi F, Bencivelli W, et al. Mortality rate and outcome factors in mixed cryoglobulinaemia: the impact of hepatitis C virus. Scand J Rheumatol 2010;39:167-170.

11. Terrier B, Semoun O, Saadoun D, Sène D, Resche-Rigon M, Cacoub P. Prognostic factors in patients with hepatitis $C$ virus infection and systemic vasculitis. Arthritis Rheum. 2011 Jun;63(6):1748-57.

12. Guillevin L, Pagnoux C, Seror R, Mahr A, Mouthon L, Le Toumelin P. The Five-Factor Score revisited: assessment of prognoses of systemic necrotizing vasculitides based on the French Vasculitis Study Group (FVSG) cohort. Medicine (Baltimore) 2011, 90:19-27.

13. Terrier B, Krastinova E, Marie I, Launay D, Lacraz A, Belenotti P, et al. Management of non infectious mixed cryoglobulinemia vasculitis: data from 242 cases included in the CryoVas survey. Blood. 2012 Jun 21;119(25):5996-6004

14. Terrier B, Carrat F, Krastinova E, Marie I, Launay D, Lacraz A, et al. Prognostic factors of survival in patients with non-infectious mixed cryoglobulinaemia vasculitis: 
data from 242 cases included in the CryoVas survey. Ann Rheum Dis. 2013 Mar;72(3):374-80.

15. Saadoun D, Sellam J, Ghillani-Dalbin P, Crecel R, Piette JC, Cacoub P. Increased risks of lymphoma and death among patients with non-hepatitis $C$ virus-related mixed cryoglobulinemia. Arch Intern Med. 2006 Oct 23;166(19):2101-8.

16. Terrier B, Launay D, Kaplanski G, Hot A, Larroche C, Cathébras $P$, et al. Safety and efficacy of rituximab in nonviral cryoglobulinemia vasculitis: data from the French Autoimmunity and Rituximab registry. Arthritis Care Res (Hoboken). 2010 Dec;62(12):1787-95.

17. Cacoub P, Terrier B, Saadoun D. Hepatitis C virus-induced vasculitis: therapeutic options. Ann Rheum Dis. 2014 Jan;73(1):24-30

18. Saadoun D, Resche-Rigon M, Thibault V, Piette JC, Cacoub P. Antiviral therapy for hepatitis $C$ virus-associated mixed cryoglobulinemia vasculitis: a long-term follow up study. Arthritis Rheum 2006;54(11):3696-706.

19. Terrier B, Saadoun D, Sène D, Sellam J, Pérard L, Coppéré B, et al. Efficacy and tolerability of rituximab with or without PEGylated interferon alfa-2b plus ribavirin in severe hepatitis $C$ virus-related vasculitis: a long-term followup study of thirty-two patients. Arthritis Rheum. 2009 Aug;60(8):2531-40.

20. Landau D-A, Saadoun D, Halfon P, Martinot-Peignoux M, Marcellin P, Fois E, et al. Relapse of hepatitis $C$ virus-associated mixed cryoglobulinemia vasculitis in patients with sustained viral response. Arthritis Rheum 2008;58(2):604-11.

21. Saadoun D, Resche Rigon M, Pol S, Thibault V, Blanc F, Pialoux G, et al. PegIFNaRibavirin/Protease inhibitor combination in severe hepatitis $C$ virus associated mixed cryoglobulinemia vasculitis. J Hepatol 2014;

22. Gragnani L, Fabbrizzi A, Triboli E, Urraro T, Boldrini B, Fognani E, et al. Triple antiviral therapy in hepatitis $C$ virus infection with or without mixed cryoglobulinaemia: A prospective, controlled pilot study. Dig Liver Dis Off $\mathrm{J}$ Ital Soc Gastroenterol Ital Assoc Study Liver 2014;46(9):833-7.

23. European Association for Study of Liver. EASL Clinical Practice Guidelines: management of hepatitis C virus infection. J Hepatol 2014;60(2):392-420.

24. Cacoub P, Delluc A, Saadoun D, Landau DA, Sene D. Anti-CD20 monoclonal antibody (rituximab) treatment for cryoglobulinemic vasculitis: where do we stand? Ann Rheum Dis 2008;67(3):283-7.

25. De Vita S, Quartuccio L, Isola M, Mazzaro C, Scaini P, Lenzi M, et al. A randomized controlled trial of rituximab for the treatment of severe cryoglobulinemic vasculitis. Arthritis Rheum 2012;64(3):843-53.

26. Sneller MC, Hu Z, Langford CA. A randomized controlled trial of rituximab following failure of antiviral therapy for hepatitis $C$ virus-associated cryoglobulinemic vasculitis. Arthritis Rheum 2012;64(3):835-42. 
27. Dammacco F, Tucci FA, Lauletta G, Gatti P, De Re V, Conteduca V, et al. Pegylated interferon-alpha, ribavirin, and rituximab combined therapy of hepatitis $C$ virus-related mixed cryoglobulinemia: a long-term study. Blood 2010;116(3):343-53.

28. Saadoun D, Resche Rigon M, Sene D, Terrier B, Karras A, Perard L, et al. Rituximab plus Peg-interferon-alpha/ribavirin compared with Peg-interferon-alpha/ribavirin in hepatitis C-related mixed cryoglobulinemia. Blood 2010;116(3):326-34.

29. Saadoun D, Pineton de Chambrun M, Hermine O, Karras A, Choquet S, Jego P, et al. Using rituximab plus fludarabine and cyclophosphamide as a treatment for refractory mixed cryoglobulinemia associated with lymphoma. Arthritis Care Res 2013;65(4):643-7.

30. Monti G, Pioltelli P, Saccardo F, Campanini M, Candela M, Cavallero G, et al. Incidence and characteristics of non-Hodgkin lymphomas in a multicenter case file of patients with hepatitis $\mathrm{C}$ virus-related symptomatic mixed cryoglobulinemias. Arch Intern Med. 2005 Jan 10;165(1):101-5. 
Table 1. Main demographic and clinical features of patients with cryoglobulinemia vasculitis according to hepatitis $\mathrm{C}$ virus (HCV) status and immunochemical type of the cryoglobulin (from ref 1 ).

\section{HCV status}

- Type of the cryoglobulin

- Number of patients

- Age (years)

- Female (\%)

\section{Clinical features}

- Skin (\%)

- Purpura (\%)

- Necrosis (\%)

- Ulcers (\%)

- Livedo (\%)

\begin{tabular}{|l|l|l|}
\hline 86 & 83 & 76 \\
\hline 69 & 75 & 71 \\
\hline 28 & 16 & 1 \\
\hline 27 & 14 & 4 \\
\hline 13 & 2 & 4 \\
\hline
\end{tabular}

HCV positive

Mixed

$64 \quad 242$

65

$63 \quad 60$

56

69

54 
- Joints (\%)

\begin{tabular}{|c|c|c|}
\hline 28 & 40 & 53 \\
\hline 44 & 52 & 74 \\
\hline 0 & 2 & 9 \\
\hline 30 & 35 & 34 \\
\hline 0 & 5 & 7 \\
\hline
\end{tabular}

Biological features

- Cryoglobulin (g/L)

\begin{tabular}{l|l|l|}
\hline 1,55 & 0,94 & 1,04 \\
\hline 0,09 & 0,07 & 0,09 \\
\hline
\end{tabular}


Table 2. Etiologic factors in patients with cryoglobulinemia

\begin{tabular}{lcc}
\hline Etiologic factors & Trejo et al. (6) & Saadoun et al. (15) \\
\hline Number of patients & $\mathbf{4 4 3}$ & $\mathbf{1 4 3 4}$ \\
& & \\
Infection & $\mathbf{7 5 \%}$ & $\mathbf{9 2} \%$ \\
Hepatitis C virus & $73 \%$ & $91 \%$ \\
Hepatitis B virus & $3 \%$ & $0.5 \%$ \\
HIV & $19 \%$ & $0.5 \%$ \\
Auto-immune disorders & $\mathbf{2 4 \%}$ & $\mathbf{3} \%$ \\
Primary Sjögren syndrome & $9 \%$ & - \\
Systemic lupus erythematosus & $7 \%$ & - \\
Rheumatoid artritis & $0.5 \%$ & - \\
Hematologic disorders & $\mathbf{7 \%}$ & $\mathbf{2 . 5} \%$ \\
Non-Hodgkin lymphoma & $4 \%$ & - \\
Chronic lymphocytic leukemia & $1 \%$ & - \\
Multiple myeloma & $1 \%$ & - \\
Hodgkin lymphoma & $0.5 \%$ & - \\
Essential cryoglobulinemia & $\mathbf{1 1} \%$ & $\mathbf{2 . 5} \%$ \\
\hline
\end{tabular}


Figure 1: Survival rates (Kaplan Meier) in cryoglobulinemia vasculitis according to the type of cryoglobulin (I, II or III) and hepatitis $\mathrm{C}$ virus (HCV) status (from ref 1).

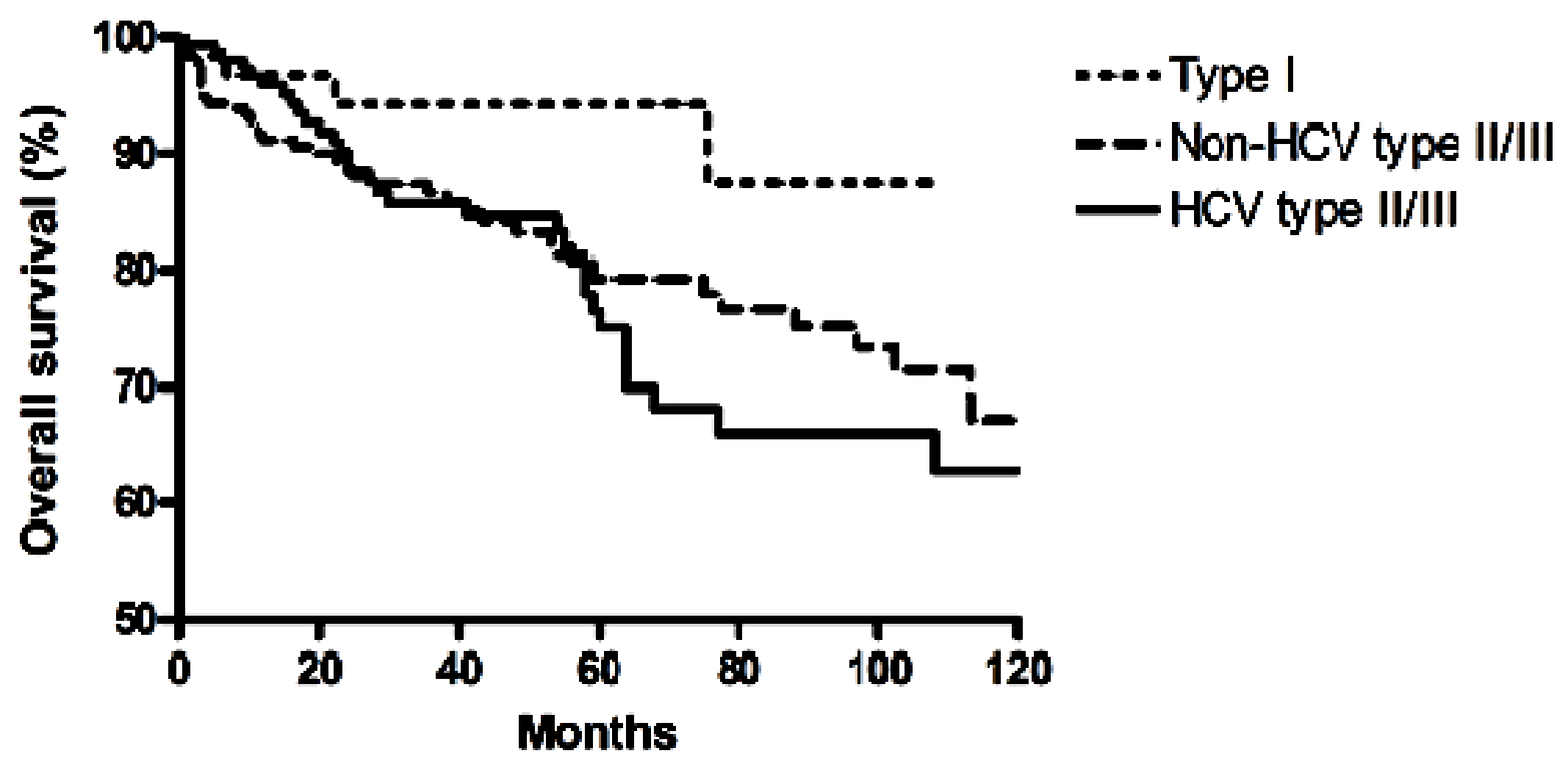


Figure 2. Cryoglobulin immuno-typing and related underlying diseases

(lg, immunoglobulin)

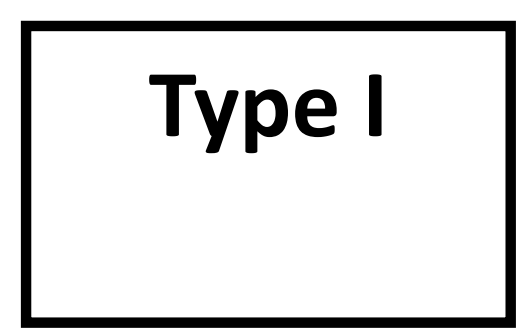

Monoclonal Ig

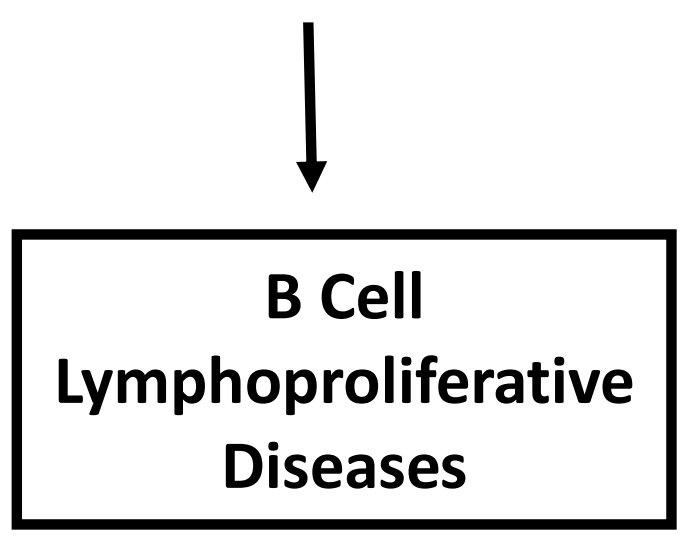

Mixed Cryoglobulinemia

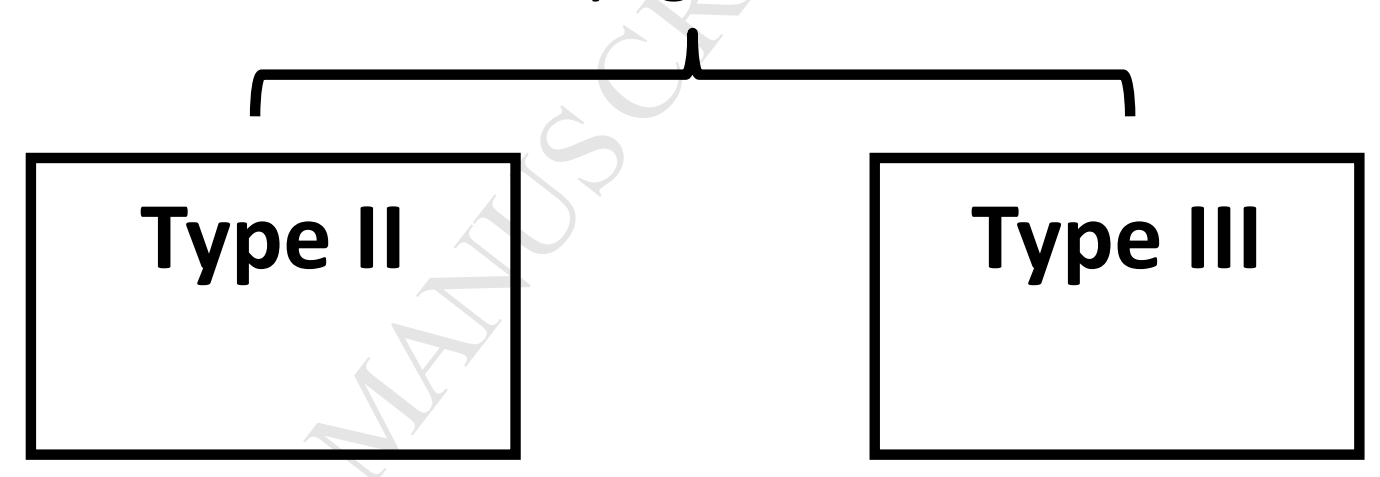

Monoclonal Ig

+ Polyclonal Ig

Polyclonal Ig

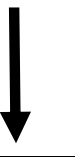

Chronic infections (hepatitis $C$ virus +++)

B Cell Lymphoproliferative Diseases

Auto-immune Diseases

« Essential » 
Figure 3. Treatment of HCV-related mixed cryoglobulinemia vasculitis according to the presentation.

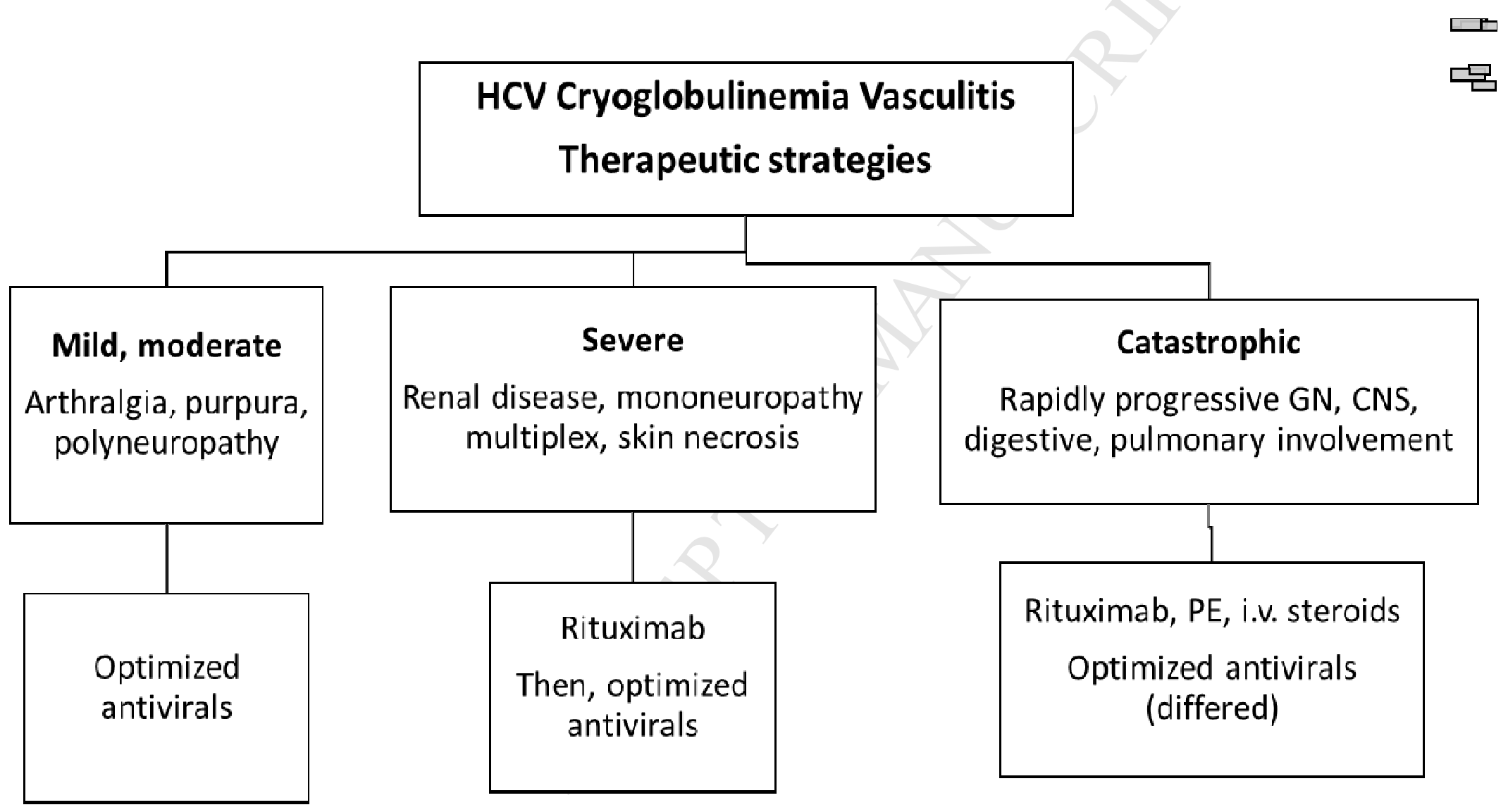




\section{Clinical significance}

- In HCV-negative patients with cryoglobulinemic vasculitis (CryoVas), pulmonary, gastrointestinal and renal involvement, and age $>65$ years are associated with death.

- In HCV-positive patients with CryoVas, antivirals are associated with a good prognosis whereas use of immunosuppressant is associated with a poor outcome.

- Increased risk of lymphoma exists in both forms.

- For HCV patients with severe vasculitis, rituximab, with or without plasmapheresis, is required before initiation of antiviral therapy. 